intervention. Among the functional issues that are not yet illuminated are the specificity of particular RHR combinations towards particular $\kappa \mathrm{B}$ sites and the ability of RHR proteins to activate transcription. Moreover, it is unclear how RHR proteins can interact with many other transcription factors.

Finally, the evolutionary significance of the resemblance to immunoglobulins, although thought-provoking, is still unclear. NF- $\kappa \mathrm{B}$ and its relatives are involved in important cellular responses that protect animals from various pathogenic challenges. Our recent knock-out of the p50 gene produces serious defects in both specific and nonspecific immune responses $^{12}$, showing clearly the import- ance of this protein. Perhaps the structures will provide the clue for designing inhibitors or activators with therapeutic value.

David Baltimore and Amer A. Beg are in the Department of Biology, Massachusetts Institute of Technology, Cambridge, Massachusetts 02139, USA.

\title{
Eugene Wigner (1902-1995)
}

Eugene Wigner died in Princeton, New Jersey on 1 January 1995. In his passing we have lost one of the last of the giants who contributed so brilliantly to the evolution of the field of wave mechanics starting in the 1920s.

He was born in 1902 into the stimulat. ing Jewish community of Budapest. Under the influence of his beloved teacher, László Rátz, and a boyhood friendship with John von Neumann, he rapidly developed the mathematical talents which were a permanent part of his strength.

In fulfilment of a promise to his practical father, he went to Berlin to study chemistry and chemical engineering, of which he soon became a master. However, his heart and all his spare time were devoted to the activities of the brilliant group of theoretical physicists then in or near Berlin. At that time, several other Hungarians such as Michael Polanyi and Leo Szilard, as

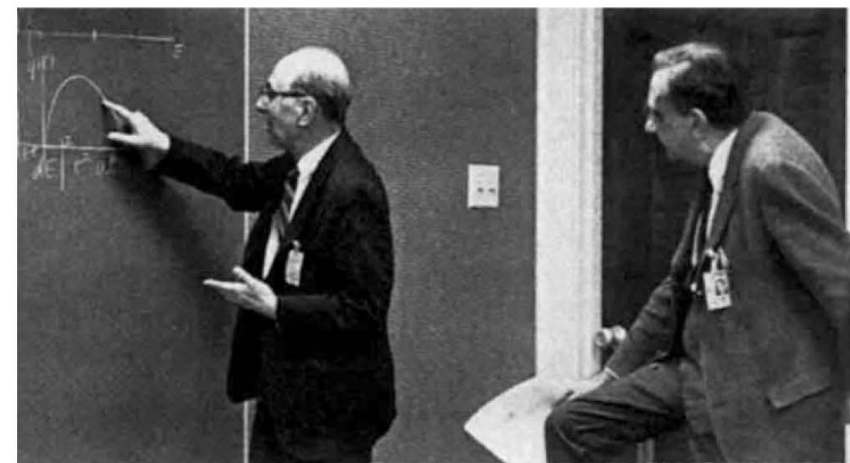

Eugene Wigner (at blackboard) discussing physics with fellow Hungarian Edward Teller. From The Recollections of Eugene P. Wigner by Andrew Szanton (Plenum, New York, 1992) well as von Neumann, were also in Berlin and formed close bonds. Polanyi, in fact, arranged for Wigner to receive an appointment as assistant to the theoretical physicist Richard Becker, which was then followed by an appointment in Göttingen where, to Wigner's joy, he and von Neumann were reunited. It was during this period that Wigner introduced the enormously powerful methods of group theory into physics.

Von Neumann foresaw, even in the mid-1920s, that there would probably be another great war and it would be coupled to the rising anti-semitism that he was witnessing in Germany. So when in 1929 Princeton University offered him a professorship with tenure he was delighted to establish partly American roots. As he wished, however, to retain links with Göttingen, he suggested that he and Wigner share the appointment. Princeton agreed, being anxious to capture von Neumann on any basis. Thus in $\mathbf{1 9 3 0}$ Wigner began his lifelong career in the United States. I became his first American graduate student in 1932 and thus formed a long-standing relationship.
Von Neumann transplanted easily; Wigner did not. He was a lonely man in Princeton for the first few years. Hitler, however, cancelled his German appointment in 1933 and Wigner began to establish roots in what became his most beloved home. The 1930 s represented intensely productive years for Wigner, during which he made weighty contributions to solid-state physics, nuclear

tion of the first experimental working reactor, which went critical in December 1942 , Wigner, with a small group of highly talented individuals that included Alvin M. Weinberg, Gale Young and Edward C. Creutz, was laying out detailed engineer. ing plans for the construction of the gigantic nuclear reactors that were ultimately built at Hanford. This work went hand-in-hand with much experimental work of a technical nature. Wigner's training as a chemic. al engineer was finally paying off on a big scale. He suffered some consternation when General Leslie Groves turned control of the construction of the reactors over to the Dupont Company. Wigner feared that the delays that would inevitably be involved in such a transition could prove fatal if it came to a close race with the Germans in taking advantage of nuclear fission. Nevertheless, he continued to play a magnificently responsible role in co-

theory and the formulation of the group representations associated with the Lorentz transformation. His pioneering work in nuclear physics, based partly on the use of group theory, was to earn him a Nobel Prize in 1963.

As the Second World War approached, Wigner became increasingly apprehen. sive about the turn of international affairs. When the discovery of nuclear fission was announced early in 1939, he was prepared to collaborate with Szilard and Enrico Fermi who were now at Columbia University to see if it would be possible to create a nuclear chain reaction. The rest is history. Once it was clear that at least two neutrons were produced during fission, that plutonium was doubtless fissionable and that pure graphite could serve as a moderator, all of Wigner's talents, active and latent, were unleashed. In 1942 he and many colleagues settled at the University of Chicago where more space for the work was available, to continue their work with renewed activity under the leadership of Arthur Compton.

While Fermi was beginning construc- operation with the Dupont team.

Wigner so abhorred the thought that the first full-scale use of nuclear fission would be to destroy human lives that he signed the 1945 petitions protesting against any use of nuclear bombs in Japan. He, and many of his team, including Weinberg and Young, began in 1946 to develop plans for nuclear reactors (including breeders) for peaceful purposes. Once it became clear, however, that the field would become embroiled in complex political matters, he returned to academic life in 1947. There he focused once again on theoretical and nuclear physics but continued to advise on problems dealing with nuclear reactors. Anticipating that there would eventually be a widespread distribution of nuclear weapons, he spent much spare time at Oak Ridge working on practical plans for providing civil defence. It was part of his sense of obligation to fellow citizens and, indeed, all humanity. Frederick Seitz

Frederick Seitz is President Emeritus of the Rockefeller University, 1230 York Avenue, New York, New York 10021, USA. 